\title{
Effects of hyperbaric oxygenation therapy on symptomatic pneumocephalus
}

This article was published in the following Dove Press journal:

Therapeutics and Clinical Risk Management

6 October 2014

Number of times this article has been viewed

Wellingson Silva Paiva

Almir Ferreira de Andrade

Eberval Gadelha Figueiredo

Robson Luis Amorim

Marcelo Prudente

Manoel Jacobsen Teixeira

Division of Neurosurgery, University of São Paulo Medical School, São

Paulo, Brazil
Correspondence: Wellingson Silva Paiva Division of Neurosurgery, University of São Paulo Medical School, 255 Eneas Aguiar Street, Office 4080 São Paulo, Brazil 05403010

Tel +55 II 266 I 7226

Fax +55 || 25486906

Email wellingsonpaiva@yahoo.com.br
Background: Pneumocephalus (PNC) is defined as a pathological collection of gas within the cranial cavity. The authors studied the effects of hyperbaric oxygenation (HBO2) therapy on a group of patients with PNC, comparing them with a control group to determine the relative impact on pneumocephalus volume, clinical symptoms, and duration of hospitalization.

Methods: Twenty-four patients with PNC treated at our hospital were consecutively studied. These patients were divided into a treated group $(n=13)$ and a control group $(n=11)$. Thirteen patients (treated group) were treated with $\mathrm{HBO} 2$ therapy sessions in a monoplace hyperbaric chamber at 2.5 atmospheres with $100 \%$ oxygen concentration. The control group was treated with normobaric oxygenation.

Results: Clinical improvement was seen in all patients. In the treated group, a decrease of the gas bubble was observed on the computerized tomography scan after each session of $\mathrm{HBO} 2$. The treated group also experienced a lower rate of meningitis compared with the control group. The length of hospital stay was significantly higher in the control group compared with the treated group.

Conclusions: HBO2 therapy in selective cases may lead to clinical and radiological improvement in patients with PNC.

Keywords: cerebrospinal fluid leakage, head injury, meningitis

\section{Introduction}

Pneumocephalus (PNC) is defined as a pathological collection of gas within the cranial cavity accumulating in the epidural, subdural, subarachnoid, intraventricular, or intraparenchymal compartments. ${ }^{1-4}$ PNC is associated with several etiological factors, including head injury, surgical procedures, infection, and neoplasm. PNC is particularly frequent after head injury with concomitant skull base fractures and cerebrospinal fluid (CSF) leakage. ${ }^{1,3}$ Persistent or tension PNC may cause headache, lethargy, and neurological deterioration. Persistent PNC reflects an abnormal communication between the intradural space and external environment, creating a risk factor for central nervous system infection. ${ }^{4}$

Chiari is usually credited with the original description of PNC in 1884; however, Lecat first described a case of "aerocele" in 1741. ${ }^{4}$ The term was coined independently by Luckett in 1913 and Wolff in 1914, who radiographically demonstrated intracranial air. ${ }^{4}$ PNC may reduce brain compliance and increased intracranial pressure. ${ }^{4} \mathrm{PNC}$ has been treated by ventilating the patient with normobaric $100 \%$ oxygen, resulting in the reabsorption of nitrogen into the blood stream and reduction of the volume of the intracranial air. ${ }^{4,5}$ However, some patients may present with symptomatic PNC even 
after normobaric hyperoxygenation, increasing the risks for meningitis and prolonged length of the hospital stay.

We have used hyperbaric oxygenation ( $\mathrm{HBO} 2$ ) therapy to accelerate the process of air absorption in patients sustaining symptomatic or persistent PNC. ${ }^{1}$ The authors studied the effects of $\mathrm{HBO} 2$ therapy in a selected group of patients compared with a control group regarding the effects of $\mathrm{HBO} 2$ therapy on the decrease of the expansive effect, improvement of clinical symptoms, incidence of meningitis, and hospitalization time.

\section{Materials and methods}

Twenty-four consecutive inpatients with PNC treated at our hospital were studied: 22 inpatients presenting traumatic brain injury and 2 patients in the postoperative period, each having a cerebellar tumor. All of them presented with symptomatic pneumoencephalus. These patients were divided into a treated group $(n=13)$ and a control group $(n=11)$. Patients were divided into groups according to the order of arrival at our service. The first patient was included in the control group and subsequent patients were allocated according to the order of arrival alternating between control group and $\mathrm{HBO} 2$ group (the treated group). Table 1 summarizes the features

Table I Distribution of patients according to treatment group, age, and trauma mechanism

\begin{tabular}{llll}
\hline Group & Age (years)/sex & Trauma mechanism & GCS \\
\hline $\mathrm{HBO} 2$ & $37 / \mathrm{M}$ & MVA & 14 \\
$\mathrm{HBO} 2$ & $43 / \mathrm{F}$ & MVA & 15 \\
$\mathrm{HBO} 2$ & $43 / \mathrm{F}$ & Falls & 15 \\
$\mathrm{HBO} 2$ & $36 / \mathrm{M}$ & Falls & 13 \\
$\mathrm{HBO} 2$ & $43 / \mathrm{F}$ & Agression & 14 \\
$\mathrm{HBO} 2$ & $27 / \mathrm{F}$ & MVA & 15 \\
$\mathrm{HBO} 2$ & $35 / \mathrm{M}$ & MVA & 15 \\
$\mathrm{HBO} 2$ & $32 / \mathrm{F}$ & MVA & 15 \\
$\mathrm{HBO} 2$ & $29 / \mathrm{F}$ & Falls & 14 \\
$\mathrm{HBO} 2$ & $37 / \mathrm{M}$ & MVA & 13 \\
$\mathrm{HBO} 2$ & $5 \mathrm{I} / \mathrm{F}$ & MVA & 13 \\
$\mathrm{HBO} 2$ & $33 / \mathrm{F}$ & Postoperative & 14 \\
$\mathrm{HBO} 2$ & $4 \mathrm{M}$ & Postoperative & 15 \\
$\mathrm{NBO}$ & $48 / \mathrm{F}$ & MVA & 15 \\
$\mathrm{NBO}$ & $49 / \mathrm{M}$ & MVA & 15 \\
$\mathrm{NBO}$ & $4 \mathrm{I}$ & Falls & 15 \\
$\mathrm{NBO}$ & $38 / \mathrm{F}$ & MVA & 14 \\
$\mathrm{NBO}$ & $32 / \mathrm{F}$ & MVA & 15 \\
$\mathrm{NBO}$ & $55 / \mathrm{M}$ & Falls & 13 \\
$\mathrm{NBO}$ & $4 \mathrm{I}$ & MVA & 13 \\
$\mathrm{NBO}$ & $32 / \mathrm{M}$ & MVA & 14 \\
$\mathrm{NBO}$ & $36 / \mathrm{M}$ & MVA & 15 \\
$\mathrm{NBO}$ & $33 / \mathrm{F}$ & MVA & 15 \\
NBO & $43 / \mathrm{M}$ & Falls & 13 \\
\hline A & $\mathrm{HBO}$ & \\
\hline
\end{tabular}

Abbreviations: $\mathrm{HBO} 2$, hyperbaric oxygenation; NBO, normobaric oxygenation; M, male; F, female; MVA, motor vehicle accident; GCS, Glasgow Coma Scale. of the two groups. The inclusion criteria were hypertensive or symptomatic pneumocephalus and presence of air in more than one intracranial compartment. Previous history or clinical signs of lung or heart diseases or epilepsy were exclusion criteria. Patients with large cranial defects, those under orotracheal intubation, or those sustaining pneumoventricle that had been previously drained were also excluded. Two patients in the treated group developed symptomatic PNC after posterior fossa procedures. All patients included in this study presenting with a Glasgow Coma Scale score between 13 and 15 points in the (Table 1). Ethical approval for this study was obtained through the University of São Paulo Research Ethics Committee.

After diagnosis, patients in the treated group were submitted to $\mathrm{HBO} 2$ therapy sessions in a monoplace hyperbaric chamber at 2.5 atmospheres with $100 \%$ oxygen concentration (Sechrist Model 2500-B Monoplace Hyperbaric Chamber, Anahein, California, USA). Sessions lasted for 1 hour with a minimum interval of 12 hours between them. The number of sessions was defined according to the follow-up in computerized tomography (CT) scan. Sessions were conducted in patients until radiological remission or a maximum of 5 days of treatment. Ten patients were male and the median age of all patients was 38.5 years. The control group comprised eleven patients sustaining nonhypertensive but symptomatic PNC who were treated with normobaric oxygenation. Patients in this group underwent observation in the intensive care unit. For each control patient, catether nasal oxygen was administered continuously at $5 \mathrm{~L} / \mathrm{min}$ for 5 days. Clinical history and neurological examination (remission of headache or improvement in level of consciousness) were used as parameters to assess clinical improvement. Cranial CT scans were utilized to evaluate the radiological outcome before and after treatment. The length of hospital stay and the incidence of meningitis were compared between the two groups. Statistical analysis was performed using SPSS, version 19.0 (IBM Corporation, Amrock, NY, USA).

\section{Results}

No patient had to change the $\mathrm{HBO} 2$ protocol, and no clinical effects were observed during the acute compression and decompression phases. The treatment lasted for a maximum period of 5 days (average of 8.8 exposures/patient). Table 2 summarizes the results. Clinical improvement was observed in both groups, and it was observed after the first sessions in all treated patients with a Glasgow Coma Scale score below 15. In patients with 15 points on the Glasgow Coma Scale, improvement of headache was seen in all of them. 
Table 2 Comparison between treated and control groups

\begin{tabular}{llllll}
\hline Groups & Male/female & $\begin{array}{l}\text { Median age } \\
\text { (years) }\end{array}$ & $\begin{array}{l}\text { Infection } \\
\text { rate (\%) }\end{array}$ & $\begin{array}{l}\text { Time of radiological } \\
\text { resolution (days) }\end{array}$ & $\begin{array}{l}\text { Time of } \\
\text { hospitalization (days) }\end{array}$ \\
\hline Control group $(\mathrm{n}=\mathrm{II})$ & $08 / 03$ & 40.1 & 36.3 & 8.3 & 9.9 \\
Treated group $(\mathrm{n}=13)$ & $10 / 03$ & 38.5 & 0.0 & 3.0 & 5.8 \\
\hline
\end{tabular}

A progressive reduction of the gas bubble volume was also observed in the CT scans of all patients, with the subarachnoid air being absorbed faster than air in subdural or intraparenchymal locations (Figure 1A and B). The radiological resolution of the PNC occurred sooner in the treated group (mean $=3$ days) than in the control group (mean $=8$ days) (Figure 2A and B). The treated group developed fewer cases of meningitis compared with the control group that occurred during follow-up (Table 2).

The incidence of meningitis in the treated group was zero, while there were four cases (36.3\%) of meningitis among the 11 control patients (2 Acinetobacter baumanii, 1 Streptococcus pneumoniae, and 1 Pseudomonas aeruginosa). The length of hospital stay was longer in the control group (9.9 days) compared with the treated group (5.8 days) $(P=0.01$, MannWhitney test). No acute complications related to the $\mathrm{HBO} 2$ therapy were observed in this study. No sign of pulmonary (ie, nonacute) oxygen toxicity was verified.

\section{Discussion}

PNC tends to be small and to resolve spontaneously. The main cause of PNC is head injury. Skull fractures with dural tears are primarily responsible for the presence of intracranial air. In some cases, the air collection may acquire an expansive effect (hypertensive pneumocephalus) and be lifethreatening. ${ }^{4}$ These dural defects allow continuity between the external environment with the intradural compartment, with

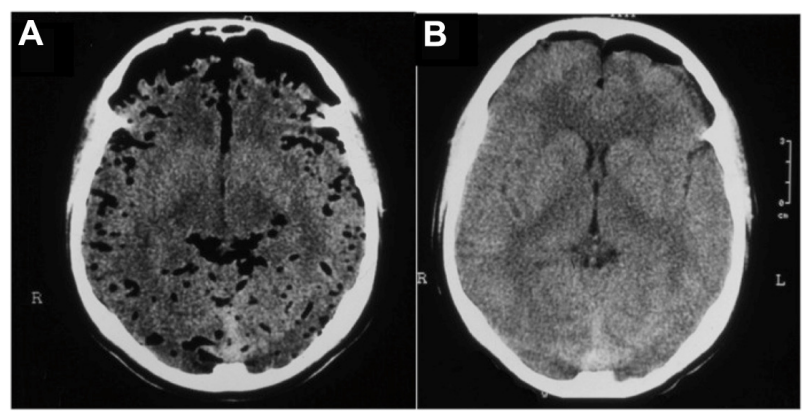

Figure I (A) Axial CT view depicting an extensive posttraumatic PNC with air bubbles located in the subaracnoid and subdural compartments. (B) Axial CT view after three sessions of $\mathrm{HBO} 2$ therapy.

Note: Notice the significant reduction of the amount of intracranial air.

Abbreviations: CT, computerized tomography; PNC, pneumocephalus; $\mathrm{HBO}$, hyperbaric oxygenation. consequent CSF leakage and higher risks of infection. In both groups, the patients had symptoms, but in the $\mathrm{HBO} 2$ group were patients with pneumocephalus hypertensive confirmed radiologically, but still fewer patients with meningitis.

PNC may also occur after neurosurgical procedures (particularly when performed with the patient in a sitting position) and anesthetic maneuvers. Analysis of factors generally associated with PNC disclosed a strongly significant correlation with copious drainage of CSF. ${ }^{1-3}$ Two mechanisms have been proposed to explain the development of tension or persistent PNC: the "inverted pop-bottle" and the "ballvalve" mechanisms. ${ }^{4}$ The inverted pop-bottle mechanism of Horowitz and Lunsford depends upon air being sucked into the cranium as CSF leaks out. ${ }^{4}$ The CSF pours as air rushes in the cranial cavity to equilibrate the pressure gradient. The sudden loss of liquid results in intracranial hypotension relative to the atmosphere and allows intracranial entrapment of air through a cranial-dural defect. ${ }^{4}$ The ball-valve mechanism of Dandy relies on a rapid increase in extracranial pressure, such as by coughing, sneezing, or blowing the nose to entrain air through a dural defect. ${ }^{4}$ Nevertheless, the defect is sealed by the dura most of time because intracranial pressure is higher than extradural pressure. Due to a tamponating effect of cortex and/or meninges, air cannot be eliminated and gradually accumulates. ${ }^{4}$

Spetzler and Wilson have proposed the use of normobaric hyperoxygenation to exchange nitrogen, an inert gas, by a more absorbable gas, oxygen. ${ }^{5}$ Normobaric hyperoxygenation

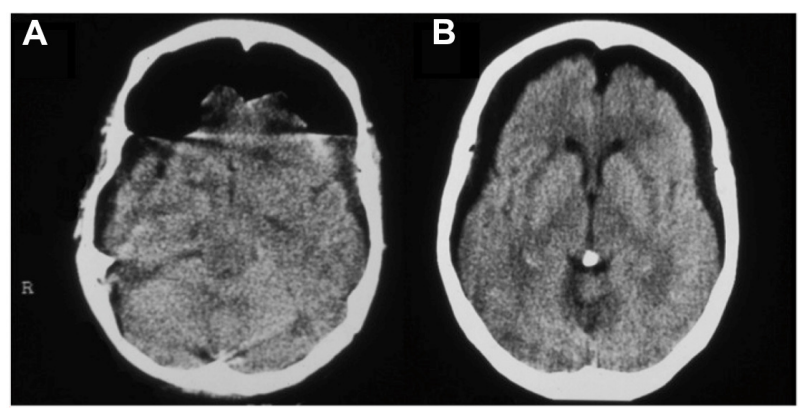

Figure 2 (A) Axial CT view depicting a subdural posttraumatic PNC. (B) Radiological evaluation after four sessions of $\mathrm{HBO} 2$ therapy demonstrates significant absorption of the intracranial air bubble.

Abbreviations: CT, computerized tomography; PNC, pneumocephalus; $\mathrm{HBO}$, hyperbaric oxygenation. 
generates a "wash out" of the air bubble reducing its volume. ${ }^{4-6}$ However, it is not always efficient. PNC may persist increasing the risks of meningitis and prolonging hospital stay.

\section{Effects of $\mathrm{HBO} 2$ on the volume of air}

$\mathrm{HBO} 2$ promotes reduction of the volume of air bubbles by replacing nitrogen. Oxygen is a rapidly diffusible gas and its diffusion results in a "wash out" mechanism of nitrogen, due the increase of the oxygen partial tension within the bubble. ${ }^{4,5}$ Nitrogen is slowly diffused and less absorbed, and it is progressively exchanged by a more absorbable gas, eg, oxygen. It can be reabsorbable from the intracranial air bubble to the blood stream, decreasing the volume of the intracranial air (Figures 1 and 2). Hence, the HBO2 and normobaric hyperoxygenation have similar modes of action; however, by increasing pressure and, consequently, tension of oxygen, $\mathrm{HBO} 2$ therapy produces an accelerated clearance of nitrogen. As the amount of intracranial gas reduces, the patient clinically improves. Additionally, HBO2 ameliorates brain metabolism, optimizes glucose utilization, and reduces intracranial pressure and gamma-aminobutyric acid (GABA, an inhibitory neurotransmitter) concentration. ${ }^{7,8}$ The sum of these effects may account for clinical and radiological improvement as observed in this subset of patients.

An interesting finding was a faster absorption of subarachnoid air when compared with subdural or intraparenchymal locations (Figure 1A and B). HBO2 augments significantly the concentration of oxygen in the subarachnoid space, which may be responsible for this rapid turnover of the subarachnoid air. ${ }^{6}$

Most nonhealing infected wounds are hypoxic. ${ }^{9-15}$ The importantly increased tissue oxygen levels in ischemic tissues during $\mathrm{HBO} 2$ treatment also stimulate neovascularization, fibroplasias, and bone remodeling. ${ }^{10-15}$ The tissues are less ischemic and the long-term healing is improved. Changes in the intracranial air dynamics associated with these wellknown prohealing properties may have some effects on the correction of the dural defect itself, promoting a long-term resolution of both PNC and CSF leakage. ${ }^{9-15}$ However, when large dural or bone defects are present, $\mathrm{HBO} 2$ therapy probably would not offer any further benefit.

\section{Effects of $\mathrm{HBO} 2$ on the incidence of meningitis}

Oxygen tension has an important role in the outcomes of infection. Leukocyte functions are greatly impaired at the low oxygen tension often observed in infected tissues. ${ }^{9,13,16,17,18}$
Additionally, high oxygen tensions result in direct bacteriostatic effects on anaerobic organisms. The effects of $\mathrm{HBO} 2$ therapy on aerobic organisms, including Staphylococcus aureus, result from improvements in phagocytosis. ${ }^{9,13,16,17,18}$

Previous study has shown remarkable results of the $\mathrm{HBO} 2$ therapy in the management of neurosurgical infections. ${ }^{12}$ Meningitis is a well-established complication of CSF leakage and PNC. It results from the contamination of subarachnoid space in contact with the external environment or sinus contents. It depends on the duration and extent of the contamination and persistence of CSF leakage. The effects on the incidence of meningitis observed in this study probably result from two independent factors: the resolution of the PNC and CSF leakage itself and the bactericidal/bacteriostatic effects of HBO2. Treatment with oxygen under normobaric conditions has no such effects. ${ }^{4}$

\section{Limitations of the study}

This study has some limitations. Although, the patients were prospectively evaluated, they were not truly randomized, since they were allocated in the treatment/control group according to order of arrival. Therefore, selection bias may have occured. However, we did not find differences in the baseline characteristics of the groups except for the presence of cerebellar hemagioblastoma in two patients in the postoperative period. The small number of patients prevented control for potential confounders such as PNC localization. Moreover, the "reduction of the bubble air" was not assessed quantitatively. When the study was developed, there were no multislice CT scans in our institution. Therefore, a quantitative measurement is not reliable. However, we could establish the time frame of resolution of the PNC, a more reliable method to compare the groups. Nevertheless, this is the first study that has given some insights into the possible benefits of the use of hyperbaric oxygenation in patients sustaining signs and symptoms of pneumocephalus.

\section{Conclusion}

This study suggests that $\mathrm{HBO} 2$ therapy when indicated in selective cases may lead to clinical and radiological improvement in patients with PNC as well as to a reduction in the incidence of meningitis and hospitalization time. $\mathrm{HBO} 2$ therapy promotes clinical improvement, reduces the incidence of infection, and shortens the length of hospital stay with a low rate of complications. By accelerating the natural "wash out" process, $\mathrm{HBO} 2$ may be useful in the management of symptomatic persistent PNC. 


\section{Authors' contributions}

AFA, EGF, WSP, and RLA carried out the design of the study, acquisition of data, analysis and interpretation of data, and drafted the manuscript. MP participated in the design of the study and interpretation of data and drafted the manuscript. MJT participated in the design of the study and helped to draft the manuscript. All authors read and approved the final manuscript.

\section{Disclosure}

The authors warrant that the article is original, is not under consideration by any other journal, and has not previously been published. Furthermore, the authors warrant that all investigations reported in the publication were conducted in conformity with the recommendations of the Declaration of Helsinki. The authors declare no conflicts of interest in this work.

\section{References}

1. de Andrade AF, Marino R, Ciquini O, Figueiredo EG, Machado AG. Guidelines for neurosurgical trauma in Brazil. World J Surg. 2001;25(9): 1186-1201.

2. Paiva WS, Saad F, Carvalhal ES, De Amorim RL, Figuereido EG, Teeixera MJ. Transorbital stab penetrating brain injury. Report of a case. Ann Ital Chir. 2009;80(6):463-465.

3. Steudel WI, Hacker H. Acute intracranial pneumocephalus: prognosis and management - a retrospective analysis of 101 cases. Neurosurg Rev. 1989;12 suppl 1:125-136.

4. Yates H, Hamill M, Borel CO, Toung TJ. Incidence and perioperative management of tension pneumocephalus following craniofacial resection. J Neurosurg Anesthesiol. 1994;6(1):15-20.

5. Spetzler RF, Wilson CB. Dural fistulae and their repair In: Youmans JR, editor. Neurological Surgery. Philadelphia: WB Saunders; 1982 : 2209-2227.
6. Hollin SA, Espinosa OE, Sukoff MH, Jacobson JH. The effect of hyperbaric oxygenation on cerebrospinal fluid oxygen. J Neurosurg. 1968;29(3):229-235.

7. Zhang Y, Yang Y, Tang H, et al. Hyperbaric oxygen therapy ameliorates local brain metabolism, brain edema and inflammatory response in a blast-induced traumatic brain injury model in rabbits. Neurochem Res. 2014;39(5):950-960.

8. Efrati S, Ben-Jacob E. Reflections on the neurotherapeutic effects of hyperbaric oxygen. Expert Rev Neurother. 2014;14(3):233-236.

9. Allen DB, Maguire JJ, Mahdavian M, et al. Wound hypoxia and acidosis limit neutrophil bacterial killing mechanisms. Arch Surg. 1997;132(9): 991-996.

10. Bouachour G, Cronier P, Gouello JP, Toulemonde JL, Talha A, Alquier P. Hyperbaric oxygen therapy in the management of crush injuries: a randomized double-blind placebo-controlled clinical trial. $J$ Trauma. 1996;41(2):333-339.

11. Brismar K, Lind F, Kratz G. Dose-dependent hyperbaric oxygen stimulation of human fibroblast proliferation. Wound Repair Regen. 1997;5(2):147-150.

12. Faglia E, Favales F, Aldeghi A, et al. Adjunctive systemic hyperbaric oxygen therapy in treatment of severe prevalently ischemic diabetic foot ulcer. A randomized study. Diabetes Care. 1996;19(12):1338-1343.

13. Granstrom G, Tjellstrom A, Branemark PI. Osseointegrated implants in irradiated bone: a case-controlled study using adjunctive hyperbaric oxygen therapy. J Oral Maxillofac Surg. 1999;57(5):493-499.

14. Larsson A, Engstrom M, Uusijarvi J, Kihlstrom L, Lind F, Mathiesen T. Hyperbaric oxygen treatment of postoperative neurosurgical infections. Neurosurgery. 2002;50(2):287-295.

15. Marx RE, Ehler WJ, Tayapongsak P, Pierce LW. Relationship of oxygen dose to angiogenesis induction in irradiated tissue. Am J Surg. 1990;160(5):519-524.

16. Knighton DR, Halliday B, Hunt TK. Oxygen as an antibiotic. A comparison of the effects of inspired oxygen concentration and antibiotic administration on in vivo bacterial clearance. Arch Surg. 1986;121(2):191-195.

17. Knighton DR, Halliday B, Hunt TK. Oxygen as an antibiotic. The effect of inspired oxygen on infection. Arch Surg. 1984;119(2):199-204.

18. Neovius EB, Lind MG, Lind FG. Hyperbaric oxygentherapy for wound complications after surgery in the irradiated head and neck: a review of the literature and a report of 15 consecutive patients. Head Neck 1997;19(4):315-322.
Therapeutics and Clinical Risk Management

\section{Publish your work in this journal}

Therapeutics and Clinical Risk Management is an international, peerreviewed journal of clinical therapeutics and risk management, focusing on concise rapid reporting of clinical studies in all therapeutic areas, outcomes, safety, and programs for the effective, safe, and sustained use of medicines. This journal is indexed on PubMed Central, CAS,

\section{Dovepress}

EMBase, Scopus and the Elsevier Bibliographic databases. The manuscript management system is completely online and includes a very quick and fair peer-review system, which is all easy to use. Visit http://www.dovepress.com/testimonials.php to read real quotes from published authors. 